\title{
Effects of caffeine on rats' barpress and maze performance
}

\author{
NANCY R. CATHEY and RANDOLPH A. SMITH \\ Ouachita Baptist University, Arkadelphia, Arkansas \\ and \\ STEPHEN F. DAVIS \\ Emporia State University, Emporia, Kansas
}

\begin{abstract}
The effects of caffeine ingestion on rats were tested through barpress and maze performance. Four adult male and 4 adult female rats were bred, yielding 39 offspring (18 control, 21 experimental). The experimental pups received $.50 \mathrm{mg} / \mathrm{ml}$ of caffeine in drinking water throughout gestation, weaning, and early adulthood; the control group received plain tap water. At 21 days of age, the pups began barpress and maze learning. The subjects were allowed a total of $8 \mathrm{~min}$ for each test on alternate days. The results were characterized by the presence of several reliable caffeine $\times$ trials interactions. Inspection of the interactions prompted the generalization that although caffeine may facilitate performance early in training, it hinders performance on later trials.
\end{abstract}

Caffeine, a methylxanthine, is a widely used central nervous system stimulant. Surveys report that $62 \%$ of Americans ingest at least $5 \mathrm{mg} / \mathrm{kg}$ per day from drinking coffee alone (West, Sobotka, Brodie, Beier, \& O'Donnell, 1986). When other sources are taken into account, it can be said that Americans consume approximately 45 million pounds of caffeine every year (Stanwood, 1990). Despite its widespread use, caffeine may have potentially detrimental effects. For example, caffeine is a possible risk factor when it is consumed in coffee by pregnant women (Gullberg, Ferrell, \& Christensen, 1986). In a 1980 position statement, the Food and Drug Administration advised pregnant women to eliminate their consumption of caffeinecontaining products.

The teratogenic effects of caffeine on the developing human fetus are of particular interest because "caffeine easily crosses the placental barrier and its clearance is substantially delayed in pregnancy" (Glavin \& Krueger, 1985 , p. 29). Prenatal administration of caffeine to rats has been shown to negatively affect mortality rate, locomotor activity, metabolic processes, immune and endocrine functions, and neurological processes (Finn \& Holtzman, 1986; Gullberg et al., 1986; West et al., 1986). Moreover, caffeine also may increase the frequency of self-injurious behavior in rats (Mueller, Saboda, Palmour, \& Nyhan, 1982).

Research (e.g., Silinsky, 1989) shows that caffeine exerts its action by blocking the presynaptic activity of

This paper was presented at the 1992 meeting of the Southwestern Psychological Association, Austin, TX. Requests for reprints should be sent to R. A. Smith, Department of Psychology, Ouachita Baptist University, Arkadelphia, AR 71998-0001. adenosine, a neurotransmitter that blocks the release of the excitatory neurotransmitter glutamate. Thus, caffeine ingestion results in an increase in the release of glutamate and leads to central nervous system arousal. Low doses of caffeine increase arousal and improve task performance, but with higher doses, anxiety and insomnia are prevalent (Glavin \& Krueger, 1985). Although prenatal caffeine administration was employed in most of the studies cited here, the behavioral effects occurred postnatally, when the rats were no longer exposed to the chemical.

Research shows that the effects of caffeine vary across time and dosage. For example, caffeine may reduce within-session decrements in ambulation and rearing in adult rats, especially during the second hour of a session (Loke \& Meliska, 1984). Changes in behavior across sessions also have been noted. Tight circling increased and then decreased in frequency in adult rats (Mueller et al., 1982). Holloway and Thor (1982) found that locomotor activity increased consistently for the first several days of testing and then decreased rapidly after an average of 14 days. They concluded that rat pups respond to increasing doses of caffeine in a curvilinear fashion, such that an initial increase in activity is followed by a decrease.

In light of these observations, we exposed rats to caffeine throughout gestation, weaning, and early adulthood to measure the drug's effect on the acquisition of behaviors requiring locomotor activity. On the basis of previous activity data showing a curvilinear function relating activity and trials in caffeine-exposed animals (e.g., Holloway \& Thor, 1982; Mueller et al., 1982), it was hypothesized that a caffeine group would display high levels of maze and barpress performance in early trials, followed by a decline as training continued. On the other hand, a non- 
caffeine control group was expected to continue to increase in performance throughout training.

\section{METHOD}

\section{Subjects}

Four adult male and 4 adult female rats were randomly selected from the colony maintained at Ouachita Baptist University. These rats were randomly assigned to 4 male-female breeding pairs. The breeding pairs were housed together for 7 days and then separated. The pups were separated from the dams at 21 days of age and housed separately. The 39 pups delivered to the 4 dams (18 control, 21 experimental) served as the subjects.

\begin{abstract}
Apparatus
A Lafayette operant conditioning chamber (Model 84012) was used for barpress training. A modified Hampton Court maze $(69.5 \times 84.5 \mathrm{~cm}$; alleys were $8.3 \mathrm{~cm}$ wide with $14.6-\mathrm{cm}$-high walls) with 11 choice points was used for all maze training.

\section{Procedure}

Upon formation, the breeding pairs were randomly assigned to the experimental (caffeine) or control (no caffeine) condition. Pairs in the experimental condition received $.50 \mathrm{mg} / \mathrm{ml}$ caffeine in plain tap water, while controls received plain tap water. Solutions were presented in 250$\mathrm{ml}$ graduated drinking tubes and were the only available liquid throughout the experiment. Lights in the room were on a 12:12-h light:dark cycle. Beginning with Day 15 of gestation, the cages were checked daily for births; new litters were considered born the previous day. As soon as they were detected, pups were marked with a permanent marker for identification. Litters were checked daily for mortalities; one pup from the caffeine group died after birth. There were no visible differences in weight between either the dams or the pups of the two groups.

At 21 days of age, the pups were weaned and began a series of tests on the barpress and maze tasks for food reinforcement. The subjects were food deprived for an average of $7 \mathrm{~h}$ (range, 6-8 h) prior to experimental testing. Otherwise food and fluids, which corresponded to those consumed by the respective dams, were freely available.

When the subjects were in the operant conditioning chamber, under conditions of continuous reinforcement, barpresses within an 8-min period were recorded. In the maze, the percent complete and actual time of completion were recorded, with an 8-min limit. The subjects alternated tasks each day until 8 sessions of each task had been completed (16 days).
\end{abstract}

\section{RESULTS AND DISCUSSION}

\section{Percent of Maze Completion}

Analysis of variance (ANOVA) of the percent of maze completion scores yielded a significant trials effect $[F(7,259)=19.64, p<.001]$. As can be seen from Figure 1 , subjects completed a higher percentage of the maze across trials. The presence of a significant drug $\times$ trials interaction $[F(7,259)=2.75, p<.01]$ indicated that statements concerning the trials effect must be considered in light of whether the subjects were caffeine exposed or not. A series of simple main effects analyses comparing the caffeine and the noncaffeine subjects on each trial was employed to probe the interaction. The results of these analyses indicated that the caffeine subjects completed a higher percentage of the maze on Trials 1 and 2 $[F(1,301)=8.56, p<.01$, and $F(1,301)=8.80, p<$ .01 , respectively].

\section{Time of Maze Completion}

The time of completion ANOVA yielded significance for the trials effect $[F(7,259)=28.59, p<.001]$ and for the drug $\times$ trials interaction $[F(7,259)=2.93, p<$ .01]. As can be seen from Figure 2, subjects generally took less time to complete the maze across trials. The results of simple main effects analyses indicated that the caffeine and noncaffeine groups differed on Trials 4 and $7[F(1,301)=4.86, p<.05$, and $F(1,301)=4.01$, $p<.05$, respectively]. The groups were marginally different on Trials 5 and $6[F(1,301)=3.38, p<.07$, and $F(1,301)=3.66, p<.06$, respectively]. Figure 2 shows that the noncaffeine group was slower on Trial 4 but faster on Trials 5, 6, and 7 .

\section{Barpress}

As with the maze data, the barpress ANOVA yielded significance for the trials effect $[F(7,259)=74.68, p<$ $.001]$ and the drug $\times$ trials interaction $[F(7,259)=$ $15.02, p<.001]$. Figure 3 shows that the number of barpresses increased reliably from the beginning to the end of testing. Simple main effects analyses indicated that the groups differed marginally on Trial $3[F(1,301)=3.56$, $p<.07$ ] and reliably on Trials 4-8 [smallest $F(1,301)=$ $5.36, p<.05]$. In these instances, the noncaffeine animals made more barpresses than did the caffeine animals.

In the present study, we investigated the relationship between caffeine and the performance of learned behaviors requiring activity. Previous research on the effects of caffeine on locomotor activities has shown an initial facilitation of the behavior followed by a decrement; the present data are similar to those results. For maze running, caffeine facilitated early performance but hindered or had no effect on later performance. For barpressing, caffeine resulted in reduced behavior across trials. Caffeine subjects completed a higher percentage of the maze during the first two trials (see Figure 1) and completed the maze in less time on Trial 4, but took more time on Trials 5-7 (see Figure 2). Caffeine subjects also produced fewer barpresses on Trials 3-8.

These results are consistent with previous research dealing with locomotor activity, in that caffeine's effects were beneficial (or less of a hindrance) on early trials. As trials continued, the performance of the caffeine subjects tended to level off, whereas the performance of noncaffeine subjects continued to improve toward a higher asymptotic level. Thus, it appears that caffeine produces beneficial effects on early trials but that caffeine produces deficits with extended testing.

The question of whether the caffeine-related decrements occurred because of prenatal or postnatal caffeine exposure is unanswered. Although the subjects in this study may have been affected prenatally by caffeine, they also continued to ingest caffeine postnatally. An extension of this research would be to test the maze and barpress performance of separate groups of animals exposed to caffeine prenatally and postnatally. 


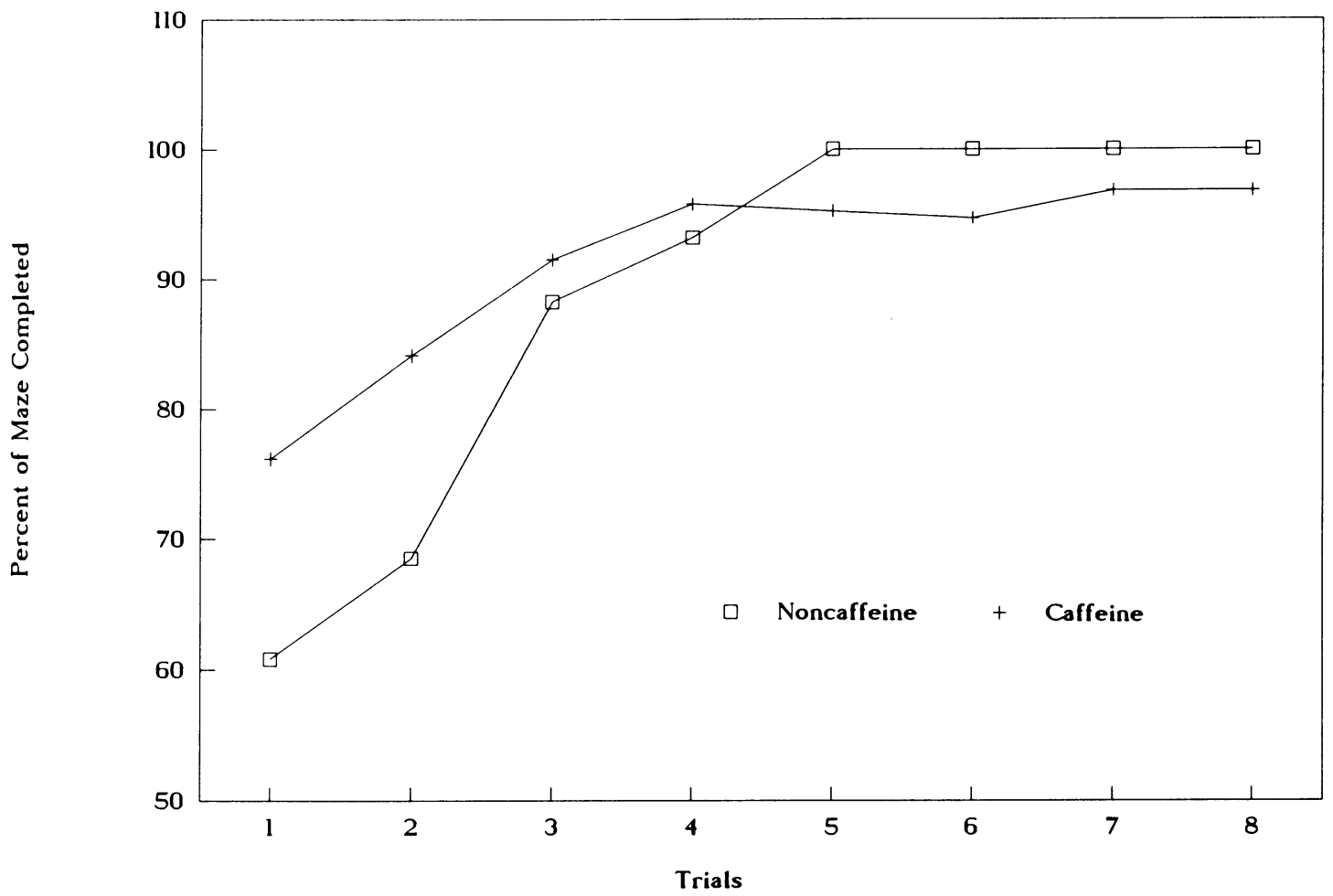

Figure 1. Percent of maze completed by caffeine and noncaffeine rats across trials.

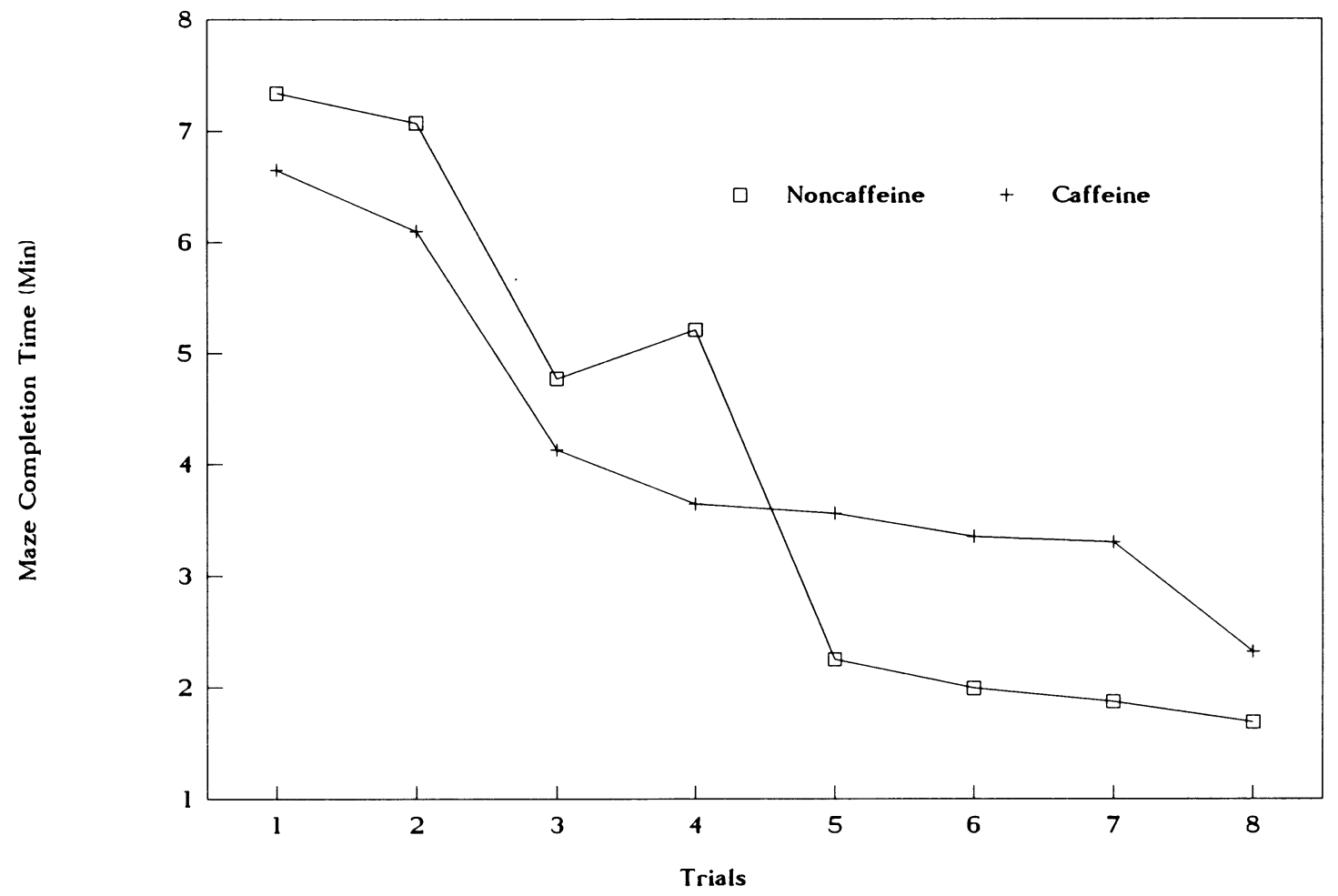

Figure 2. Maze completion time by caffeine and noncaffeine rats across trials. 


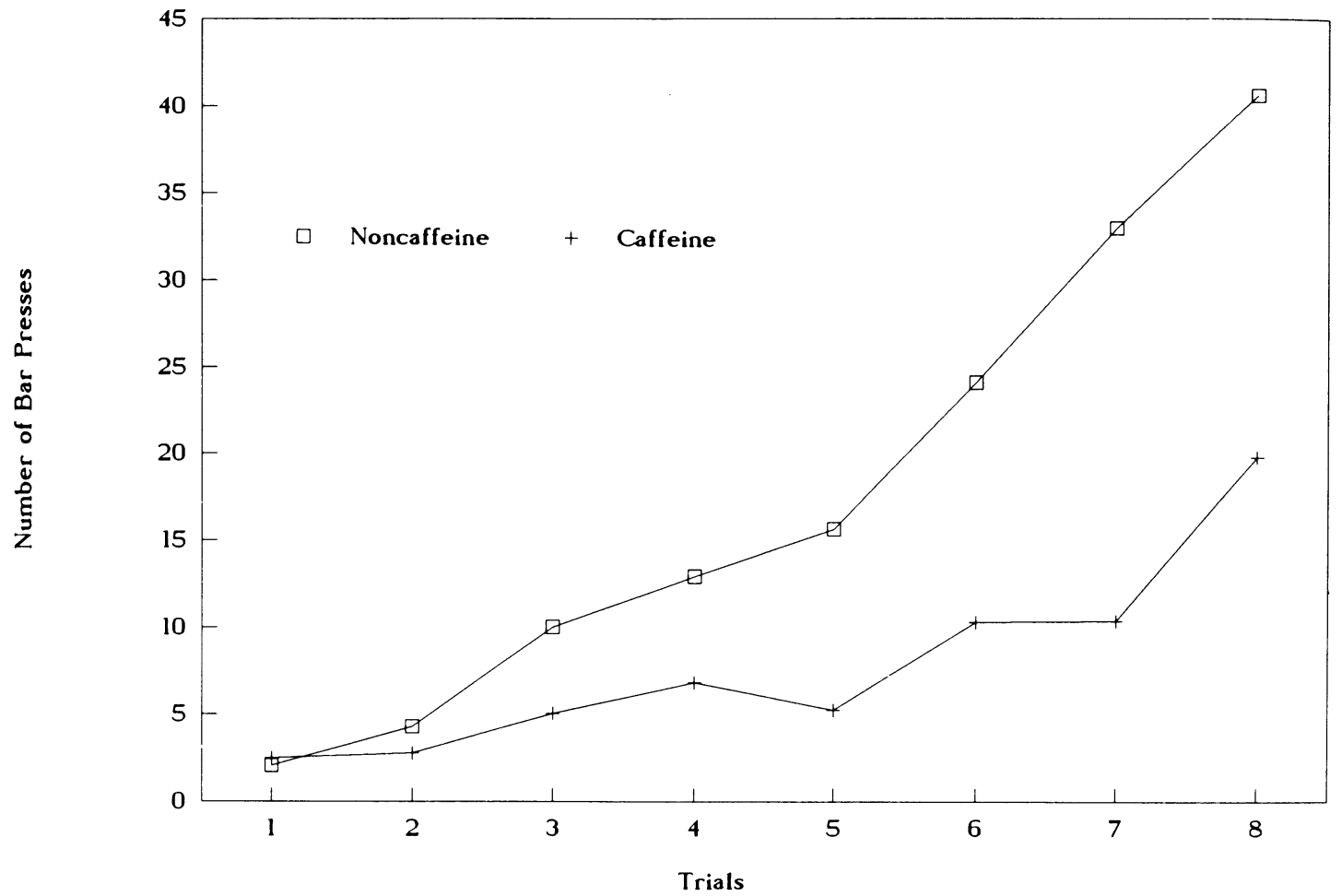

Figure 3. Number of barpresses by caffeine and noncaffeine rats across trials.

\section{REFERENCES}

FinN, I. F., \& Holtzman, S. G. (1986). Tolerance to caffeine-induced stimulation of locomotor activity in rats. Journal of Pharmacology \& Experimental Therapeutics, 238, 542-546.

Food and Drug Administration. (1980, September). Report on caffeine. Washington, DC: U.S. Department of Health and Human Services. Glavin, G. B., \& KRUEGER, H. (1985). Effects of prenatal caffeine administration on offspring mortality, open-field behavior and adult gastric ulcer susceptibility. Neurobehavioral Toxicology \& Teratology, 7, 29-32.

Gullberg, E. I., Ferrell, F., \& Christensen, H. D. (1986). Effects of postnatal caffeine exposure through dam's milk upon weanling rats. Pharmacology, Biochemistry \& Behavior, 24, 1695-1701.

Holloway, W. R., \& ThoR, D. (1982). Caffeine sensitivity in the neonatal rat. Neurobehavioral Toxicology \& Teratology, 4, 331-333.

LOKE, W. H., \& MELISKA, C. J. (1984). Effects of caffeine and nicotine on open-field exploration. Psychological Reports, 55, 447-451.
Mueller, K., Saboda, S., Palmour, R., \& Nyhan, W. L. (1982). Self-injurious behavior produced in rats by daily caffeine and continuous amphetamine. Pharmacology, Biochemistry \& Behavior, 17, 613-617.

Silinsky, E. M. (1989). Adenosine derivatives and neuronal function. Seminars in the Neurosciences, 1, 155-165.

STanwood, L. (1990). C is for coffee, chocolate, cola and ... caffeine. Current Health 2, 13, 11-13.

West, G. L., SobotKa, T. J., Brodie, R. E., Beier, J. M., \& O’DonNELL, J. W. (1986). Postnatal neurobehavioral development in rats exposed in utero to caffeine. Neurobehavioral Toxicology \& Teratology, 8, 29-43.

(Manuscript received August 22, 1992.) 